Journal of Contemporary Research in Social Sciences

ISSN : 2641-0249

Vol. 3, No. 4, pp. 69-77.

2021

Publisher: Learning Gate

DOI: 10.33094/26410249.2021.34.69.77

(C) 2021 by the authors; licensee Learning Gate

\title{
Attachment, Rejection Sensitivity, Support, Psychological Capital and Alcohol Dependency in Students
}

\author{
Tony Cassidy* \\ Professor of Child \& Family Health Psychology, School of Psychology, Ulster University, Coleraine, Northern Ireland. \\ Email: t.cassidy@ulster.ac.uk (*Corresponding Author) \\ Melanie Giles \\ PhD, Professor of Psychology, School of Psychology, Ulster University, Coleraine, Northern Ireland. \\ Email:_ml.giles@ulster.ac.uk \\ Alexis Carey \\ MSc. Health Psychologist in Training, Staffordshire University, Stoke-on-Trent, England. \\ Email: lexicarey@yahoo.co.uk
}

Received: 9 July 2021; Revised: 12 August 202 1; Accepted: 2 September 2021 ; Published: 17 September 2021

\begin{abstract}
Alcohol dependence evolves from problematic social relations hinged on attachment difficulties and fear of social rejection. This study sought to test an attachment-rejection-relationship model of the development of alcohol dependency. Emerging adults $(\mathrm{N}=762)$ of which $69.8 \%$, were female, ranging in age from 18-63 years, took part in an online survey measuring adult attachment, rejection sensitivity, loneliness, social support, psychological capital, and alcohol consumption. Analysis supports the model and shows that individuals with insecure and anxious attachment, fear of social rejection, who experience loneliness and lack of social support, and whose psychological resources are less effective, are more likely to be at risk for alcohol dependency. The role of attachment, rejection and social relations in alcohol consumption point to social problem-solving interventions. Given the childhood origins of attachment problems and fear of social rejection there is a strong case for prevention using social problem-solving.
\end{abstract}

Keywords: Attachment, Rejection sensitivity, Social support, Psychological capital, Alcohol dependency.

\section{Introduction}

In their review of reviews (Newbury-Birch et al., 2014) identified a range of factors that may predispose young people to problem drinking including, genetic factors, physical or sexual abuse in childhood, family history of alcohol problems and exposure to problem drinking in siblings or parents, and peer pressure. Arguably the influence of family history may be confused with genetic factors. Common across all these factors are social relations and adverse life circumstances. There is a substantial literature evidencing a link between lack of secure attachment and alcohol abuse (Hocking, Simons, Simons, \& Freeman, 2018) and indeed addictive behaviour in general (Nakhoul et al., 2020). Fairbairn et al. (2018) in a meta-analysis of 34 studies (total $\mathrm{N}=56,721$ ) conclude that on the balance of evidence the direction of effect is that attachment insecurity precedes both alcohol problems and problems in adult relationships. Levitt and Leonard (2015) investigated relationship specific drinking in 470 couples over the first nine years of marriage and found that it was mediated by insecure (anxious) attachment. The link between anxious and avoidant attachment and alcohol consumption and relationships was further investigated in a study of young adults and concluded that attachment issues 
should be viewed as potential precursors to alcohol problems (Goldstein, Haller, Mackinnon, \& Stewart, 2019).

Rejection sensitivity describes individuals who fear social rejection and tend to react to social cues in manner consistent with their fear (Liu, Kraines, Massing-Schaffer, \& Alloy, 2014). It is a risk factor for depression (Chango, McElhaney, Allen, Schad, \& Marston, 2012; Liu et al., 2014) and has been associated with interpersonal aggression and borderline personality disorder (Chesin, Fertuck, Goodman, Lichenstein, \& Stanley, 2015; Lawson \& Brossart, 2013). Gao, Assink, Cipriani, and Lin (2017) in a meta-analytic review of 75 studies conclude that there is a longitudinal and stable relationship between rejection sensitivity and anxiety, depression and loneliness sufficient for them to recommend that it should be a focus in risk assessment and intervention for mental health problems. Marin and Miller (2013) in a review of 76 long term studies suggest that rejection sensitivity is linked to susceptibility to infectious diseases.

Evidence suggests that rejection sensitivity is learned as a consequence of previous experiences of social rejection (Romero-Canyas, Downey, Berenson, Ayduk, \& Kang, 2010) and is linked to harsh parenting, family conflict, and early childhood trauma (Downey, Khouri, \& Feldman, 1997; Godleski, Eiden, Kachadourian, \& Lucke, 2019). The latter authors tested an etiological model of rejection sensitivity in 227 families from infancy to adolescence and concluded that it is an outcome of diverse negative childhood experiences largely related to problematic attachment. Among the specific factors were father's alcohol problems and harsh mothering. Other research has linked rejection sensitivity to early interpersonal experiences of prejudice and exclusion because of ethnic group membership (Pachankis, Hatzenbuehler, \& Starks, 2014). These authors also conclude that rejection sensitivity interacts with aspects of the social environment to predict important health-related behaviour in adolescents and is associated with social withdrawal and loneliness (Watson \& Nesdale, 2012). In one rare study looking at rejection sensitivity and alcohol problems the authors express surprise that the link has not been more fully explored (Laws, Ellerbeck, Rodrigues, Simmons, \& Ansell, 2017). They found that social rejection by others in a relationship was linked to daily alcohol consumption.

Thus far the evidence reviewed suggests that a) insecure / problematic attachment is linked to alcohol use, b) there is a link between problematic attachment and rejection sensitivity, and c) rejection sensitivity is linked to emotional problems and health-related behaviours. This would seem to allow the hypothesis that rejection sensitivity might also be related to alcohol use.

Research has also shown that both insecure and anxious attachment and rejection sensitivity are related to relationship difficulties (Downey, Feldman, \& Ayduk, 2000; Downey \& Feldman, 1996; Downey., Mougios, Ayduk, London, \& Shoda, 2004). As of course is alcohol abuse (Fischer \& Wiersma, 2012; Leonard \& Eiden, 2007). The evidence is that alcohol abuse follows from attachment insecurity rather than vice versa (Fairbairn et al., 2018).

Attachment is related to social support in complex ways and has been shown to mediate the impact of child abuse (Struck et al., 2020). In adults social support is perhaps the key mediator of stress and trauma on mental health and wellbeing (Taylor, 2011). Insecure attachment interacts with ineffective support seeking in couples leading to problems in relationships (Khodarahimi, Hashim, \& MohdZaharim, 2016; McLeod, Berry, Hodgson, \& Wearden, 2020). Social support is a key element of any intervention to change problem drinking behaviour (McGaffin, Deane, Kelly, \& Blackman, 2018) and is also implicated as a causal factor in alcohol abuse (Hamdan-Mansour, 2016).

Drawing on the well-established construct of psychological capital in the domain of work, Fred Luthans, Youssef, Sweetman, and Harms (2013) suggest that it might be usefully applied to other domains including personal relationships and health (Fred Luthans \& Youssef-Morgan, 2017). Other research has applied the model to mental health and substance abuse (Krasikova, Lester, \& Harms, 2015). These researchers found that psychological capital predicted better mental health and lower alcohol consumption in almost 2,000 army personnel following a tour of duty. Psychological capital is based on four constructs, hope, efficacy, resilience and optimism (acronym HERO), each with a 
substantial literature as psychological resources in the field of stress, health and wellbeing (Fred Luthans \& Youssef-Morgan, 2017).

Given the literature reviewed above a possible model for predicting problematic alcohol consumption was proposed and is shown in Figure 1.

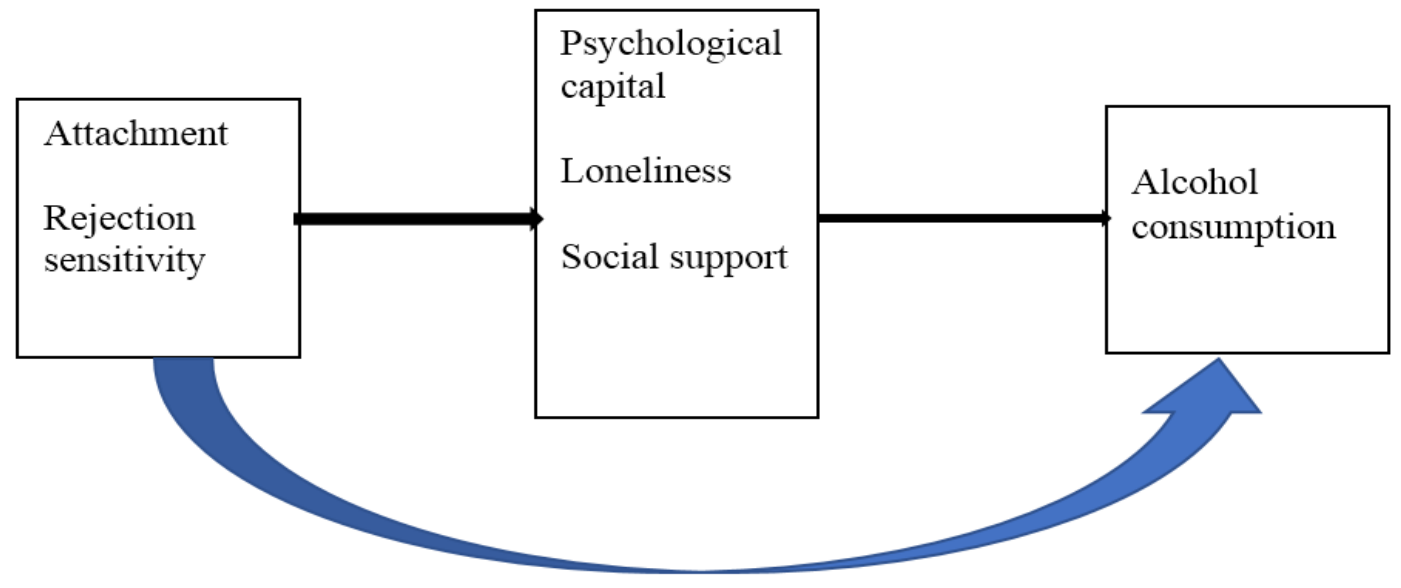

Figure-1.

Path model of the predictors of alcohol consumption.

\section{Methodology}

Design: An online survey using questionnaire data collection was used to explore the variables identified in the model at Figure 1.

Participants: The sample consisted of 762 participants (532 female and 230 females) representing a convenience sample of emerging adults. The participants ranged in age from 18 to 26 years $(M=22.32$, $S D=2.20)$.

Measures: Participants were asked for their age and sex before completing the following measures.

Attachment: The Revised Hazan and Shaver (1987) three-item questionnaire designed to measure adult attachment was employed. The three attachment styles are secure, anxious, and avoidant (Hazan \& Shaver, 1987). Secure: typically describe romantic relationships as amicable, trusting, and happy (Hazan \& Shaver, 1987). Such individuals are accepting of their partners and tend to have long satisfying relationships (Hazan \& Shaver, 1987). Anxious: typically view lovers in a neurotic way, with a constant need for reciprocation and support (Hazan \& Shaver, 1987). Avoidant individuals are typically apprehensive of intimacy, experiencing emotional highs and lows during relationships (Hazan \& Shaver, 1987). This measure demonstrates good internal consistency across the three categories (secure: $\alpha=$ 0.82; anxious: $\alpha=0.76$; avoidant: $\alpha=0.82$ ) (Fraley, Waller, \& Brennan, 2000).

Alcohol use: The Alcohol Use Disorders Identification Test (AUDIT) (Babor, Higgins-Biddle, Saunders, \& Monteiro, 2001) was developed by the World Health Organization (WHO) as a self-report screening test to identify alcohol disorders. The 10-item scale covers 3 symptom areas: hazardous use, dependence symptoms, and harmful use. All item scores range from 0 to 4 and are commonly summarized to provide an overall measure of hazardous drinking. Scores range from $0-40$ and it has been established that scores of 0-7 indicate low risk, 8-15 indicates increasing risk, 16-19 indicates higher risk, and scores of over 20 indicate potential dependency.

Psychological Capital: Psychological Capital, defined by Luthans, Youssef-Morgan, and Avolio (2015) is an individual's positive psychological state of development that is made up of four constructs; Resilience, Hope, Optimism and Self- Efficacy. A total score on Psychological Capital obtained by summing these four constructs is used in analysis. The Compound PsyCap (CPC-12) Scale is a composite measure of hope, resilience, self-efficacy, and optimism, encompassing 12 items. Each of the 
four components is reported on a 6-point Likert scale from Strongly Disagree (=1) to Strongly Agree (=6). It measures psychological capital in a universal manner. The CPC-12 has been demonstrated to have good reliability and external validity (Lorenz, Beer, Pütz, \& Heinitz, 2016). In this study, the Cronbach's alpha for the CPC-12 scale was 0.93 .

Perceived social support: Perceived levels of social support from family and peers were assessed by employing the Perceived Social Support Scale (PSSS) (Procidano \& Heller, 1983). This measure consists of two 20-item subscales focusing on perceived social support from both family members and friends. Identical wording is used on both subscales, apart from modifying the referent of the statement (e.g. "Members of my family are good at helping me solve problems" vs. "My friends are good at helping me solve problems"). The measure assesses a range of instances of support including emotional, information, feedback and reciprocity (i.e. provision of support by the individual). In the present study the Cronbach Alpha values were family support $(\alpha=0.81)$, and support from friends $(\alpha=0.83)$.

Rejection Sensitivity Questionnaire (Downey \& Feldman, 1996): The rejection sensitivity questionnaire assesses "generalized expectations and anxiety about whether significant others will meet one's needs for acceptance or will be rejecting" (Downey \& Feldman, 1996). The 18-item scale presents hypothetical requests of people close to an individual (e. g. "You ask your boyfriend/girlfriend if they really love you", "You ask your parents for extra money to cover living expenses"). Participants are required to state how anxious they would feel about making the request and how they think the person will respond to the request on a six-point Likert scale. When answering the first part of each question, 1 represents "Very Unconcerned" and 6 represents "Very Concerned" on the Likert scale. For the second part of each question 1 represents "Very Unlikely" and 6 represents "Very Likely". It is scored by reversing the likelihood estimates for all items, summing these products and dividing the total by 18 (Brookings, Zembar, \& Hochstetler, 2003). Internal reliability was satisfactory with a Cronbach's alpha value of 0.92. Downey and Feldman (1996) reported a mean (std. deviation) of 9.69(3.07), an internal consistency reliability of 0.81 and test-retest reliability of 0.83 .

Loneliness: This was measured by a short 3-item scale developed by Hughes, Waite, Hawkley, and Cacioppo (2004) for use in surveys. It was developed from the R-UCLA Loneliness Scale (Russell, Peplau, \& Cutrona, 1980). The scale had an Alpha of 0.72.

\section{Results}

In terms of AUDIT scores $154(20.2 \%)$ were in the low-risk category, $275(36.1 \%)$ were in the increasing risk category and $184(24.1 \%)$ were in the higher risk category. A total of $149(19.6 \%)$ scored over 20 hence were deemed to be potentially alcohol dependent. Mean scores for males $(\mathrm{M}=8.87$, $\mathrm{Sd}=4.65)$ and females $(\mathrm{M}=8.37, \mathrm{Sd}=4.50)$ did not differ significantly nor was there any significant relationship between sex and AUDIT category based on chi-square analysis.

Hierarchical Multiple Regression Analysis (HMRA) was used with alcohol consumption as the dependent variable. On step one age and sex were entered as predictor variables and accounted for $1 \%$ of the variance in alcohol consumption $(\beta=0.105, \mathrm{p}<0.01)$. The three dimensions of attachment were entered on step 2 and added $18 \%$ to the variance explained. Avoidant $(\beta=0.131, \mathrm{p}<0.01)$ and ambivalent $(\beta=0.214, p<0.001)$ attachment were direct predictor while secure $(\beta=-0.211, p<0.01)$ attachment was an inverse predictor. On the next step, rejection sensitivity was entered and added a further $16 \%$ to the variance explained $(\beta=0.427, \mathrm{p}<0.01)$. On step 4 social support was added and produced a further $2 \%$ of explained variance $(\beta=-0.160, p<0.01)$. We added psychological capital on the next step, and this gave an additional $8 \%$ explained variance $(\beta=-0.295, \mathrm{p}<0.01)$. On the final step loneliness was added and provided a further $2 \%$ of variance explained $(\beta=0.153, \mathrm{p}<0.01)$. See Table 1 . 
Table-1.

HMRA to identify the predictors of alcohol consumption.

\begin{tabular}{|c|c|c|c|}
\hline & B & SE.B & $\beta$ \\
\hline \multicolumn{4}{|c|}{$\mathrm{R}^{2}=0.01, \mathrm{~F}(2,759)=4.45, p<0.01$} \\
\hline Age & -0.065 & 0.023 & $-0.106^{* *}$ \\
\hline Sex & 0.079 & 0.553 & 0.005 \\
\hline \multicolumn{4}{|c|}{$\mathrm{R}^{2} \Delta=0.18, \mathrm{~F}(3,756)=55.94, p<0.001$} \\
\hline Age & -0.065 & 0.021 & $-0.106^{* *}$ \\
\hline Sex & -0.200 & 0.502 & -0.013 \\
\hline Secure Attachment & -1.094 & 0.218 & $-0.211^{* * * *}$ \\
\hline Avoidant Attachment & 0.633 & 0.204 & $0.131^{* *}$ \\
\hline Ambivalent Attachment & 1.123 & 0.180 & $0.214^{* * * *}$ \\
\hline \multicolumn{4}{|c|}{ Step 3: $\quad R^{2} \Delta=0.16, \mathrm{~F}(1,755)=187.55, p<0.001$} \\
\hline Age & -0.061 & 0.019 & $-0.099^{* * *}$ \\
\hline Sex & -0.101 & 0.450 & -0.007 \\
\hline Secure Attachment & -0.727 & 0.197 & $-0.140^{* * * *}$ \\
\hline Avoidant Attachment & 0.331 & 0.184 & 0.068 \\
\hline Ambivalent Attachment & 0.830 & 0.163 & $0.158^{* * * *}$ \\
\hline Rejection sensitivity & 1.898 & 0.139 & $0.427^{* * *}$ \\
\hline \multicolumn{4}{|c|}{ Step 4: $\quad R^{2} \Delta=0.02, \mathrm{~F}(1,754)=23.99, p<0.01$} \\
\hline Age & -0.020 & 0.020 & -0.033 \\
\hline Sex & -0.263 & 0.444 & -0.018 \\
\hline Secure Attachment & -0.742 & 0.194 & $-0.143^{* * * *}$ \\
\hline Avoidant Attachment & 0.316 & 0.182 & 0.065 \\
\hline Ambivalent Attachment & 0.792 & 0.161 & $0.151^{* * *}$ \\
\hline Rejection sensitivity & 1.798 & 0.138 & $0.405^{* * *}$ \\
\hline Support & -0.406 & 0.083 & $-0.160^{* * * *}$ \\
\hline \multicolumn{4}{|c|}{ Step 5: $\quad R^{2} \Delta=0.08, \mathrm{~F}(1,753)=107.25, p<0.01$} \\
\hline Age & -0.022 & 0.019 & -0.037 \\
\hline Sex & -0.885 & 0.420 & $-0.059^{*}$ \\
\hline Secure Attachment & -0.733 & 0.181 & $-0.142^{* * *}$ \\
\hline Avoidant Attachment & 0.321 & 0.170 & 0.066 \\
\hline Ambivalent Attachment & 0.674 & 0.151 & $0.128^{* * *}$ \\
\hline Rejection sensitivity & 1.493 & 0.133 & $0.336^{* * *}$ \\
\hline Support & -0.346 & 0.078 & $-0.136^{* * * *}$ \\
\hline Psychological Capital & -0.324 & 0.031 & $-0.295^{* * * *}$ \\
\hline \multicolumn{4}{|c|}{ Step 6: $\quad R^{2} \Delta=0.02, \mathrm{~F}(1,752)=31.81, p<0.001$} \\
\hline Age & -0.024 & 0.018 & -0.039 \\
\hline Sex & -0.715 & 0.413 & -0.048 \\
\hline Secure Attachment & -0.756 & 0.178 & $-0.146^{* * *}$ \\
\hline Avoidant Attachment & 0.419 & 0.167 & $0.087^{* * *}$ \\
\hline Ambivalent Attachment & 0.729 & 0.148 & $0.139^{* * * *}$ \\
\hline Rejection sensitivity & 1.435 & 0.130 & $0.323^{* * * *}$ \\
\hline Support & -0.328 & 0.076 & $-0.129^{* * *}$ \\
\hline Psychological Capital & -0.310 & 0.031 & $-0.283^{* * * * *}$ \\
\hline Loneliness & 0.602 & 0.107 & $0.153^{* * *}$ \\
\hline
\end{tabular}

Total $R^{2}=0.47$

Note: ${ }^{*} p<0.05 .{ }^{* *} p<0.01{ }^{* * *} p<0.001$ 
This provides some preliminary support for the model proposed in Figure 1 and suggests that individuals with insecure, avoidant, or ambivalent attachment, who are sensitive to social rejection, who have less support and lower psychological capital, and exhibit more loneliness are likely to drink more alcohol.

To test the model, we used the Structural Equation Program on AMOS 25 to build and test the fit of a path model. This can be seen in Figure 2 and supports the proposed model in Figure 1. The data were a good fit (chi-square $(5)=6.97, \mathrm{p}=0.222, \mathrm{CMIN} / \mathrm{DF}=1.395, \mathrm{GFI}=0.99$, NFI $=0.99$, IFI $=$ 0.99, CFI $=0.99$, RMSEA $=0.023$, PCLOSE $=0.876)$. See Figure 2.

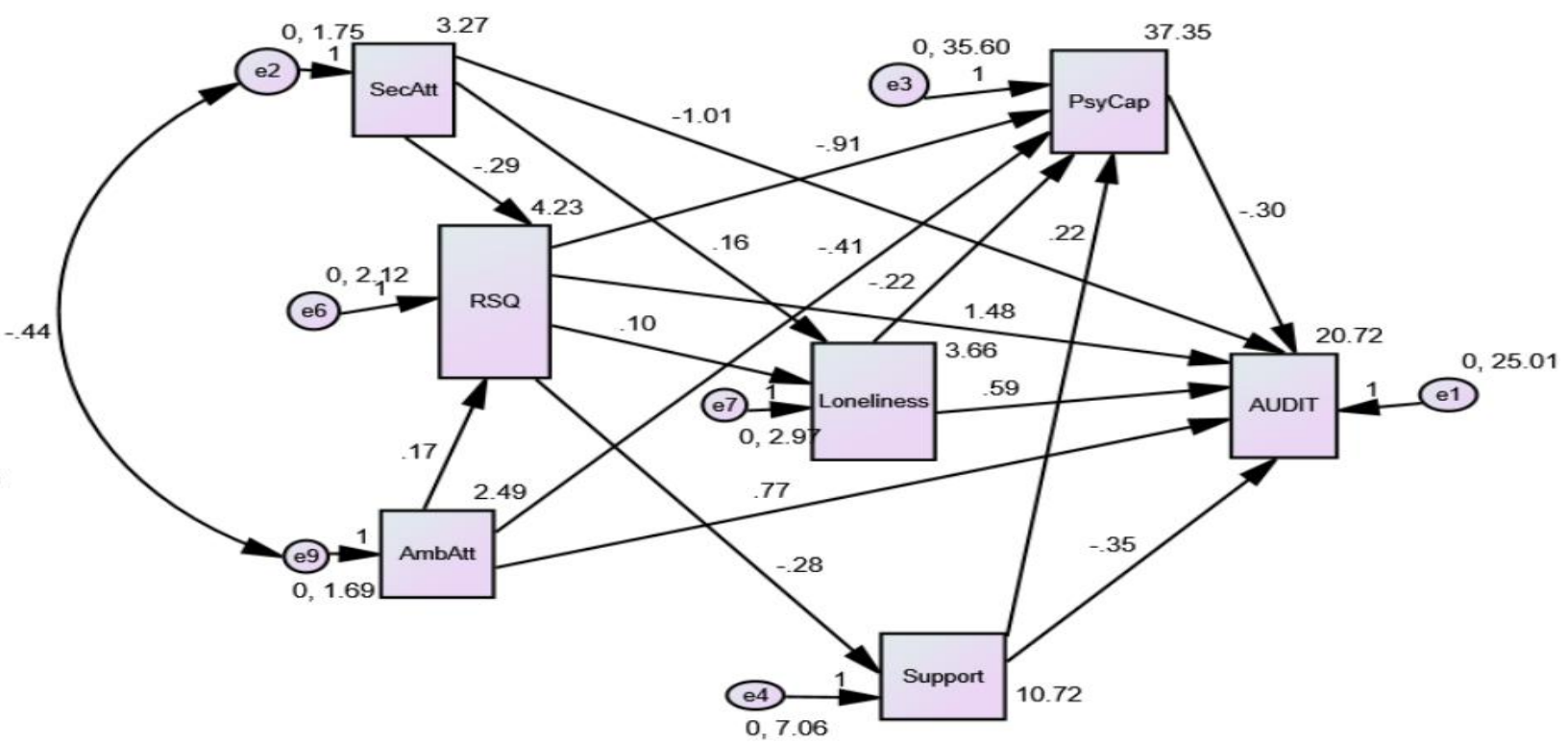

Figure-2.

Path model of the predicators of alcohol consumption, as measured by the AUDIT. (SecAtt=secure attachment; AmbAtt=Ambivalent attachment; RSQ=Rejection Sensitivity; PsyCap=Psychological Capital; AUDIT=measure of alcohol consumption.

\section{Discussion}

The aim of the current study was to test the model proposed in Figure 1, which in essence suggests that higher levels of alcohol consumption are related to several different aspects of social and intimate relations. These include insecure, ambivalent, and anxious attachment, sensitivity to social rejection, levels of perceived social support, and loneliness. In addition, these factors are mediated by psychological capital which is an indication of the psychological resilience or resourcefulness of the individual. The data do support the model. From the regression analysis we can see that attachment, rejection sensitivity, loneliness, social support, and psychological capital all contribute to the variance in alcohol consumption at a statistical level. The way in which these variable inter-relate is explicated more clearly in the path model. While the data is cross sectional the order of causality cannot be firmly established. However, based on the evidence reviewed in the introduction it is reasonable to suggest that attachment disruption and rejection sensitivity are predictive of alcohol consumption and are variables with an aetiology that links back to childhood experiences (Fairbairn et al., 2018; Godleski et al., 2019). We also know that both problem attachment style and rejection sensitivity make it difficult to form social relations (Chesin et al., 2015; Fairbairn et al., 2018) or to maintain them once formed (Downey et al., 2000; Levitt \& Leonard, 2015). The consequence of this is social withdrawal and loneliness (Watson $\&$ Nesdale, 2012) and reduced social support since that support depends on forming and maintaining social relations. Of course, not every individual who has difficulty in social attachment and is sensitive to 
rejection, or who is lonely and feels unsupported, will abuse alcohol. To some extent that will depend on their psychological resources (Krasikova et al., 2015; Luthans \& Youssef-Morgan, 2017).

What we are proposing is that individuals who have developed insecure attachment styles and who are sensitive to social rejection will find relationships difficult to establish and will experience loneliness and low levels of social support. Consequently, they may use alcohol as a crutch leading to dependency and a vicious circle. Those who find some optimism and hope and have a stronger sense of autonomy and ultimately are more resilient may be less likely to succumb to the temptation of alcohol. This is supported to some extent by the data and the path model. Again, this needs further testing in longitudinal data.

The importance of this, and our model is not new but builds on existing evidence, is the potential for prevention. The process follows on from attachment problems and fear of social rejection, both of which can be targets for intervention. There are a number of social problem-solving programmes which could be applied where an individual has already developed attachment and rejection issues (Malouff, Thorsteinsson, \& Schutte, 2007; Merrill, Smith, Cumming, \& Daunic, 2017). However, the implications are more far reaching as there is strong evidence that attachment and rejection issues originate in childhood (Fairbairn et al., 2018; Godleski et al., 2019). There are some very efficacious social problemsolving interventions for children, for example the I Can Problem Solve (ICPS) programme - formerly called the Interpersonal Cognitive Problem-Solving programme (Shure, 1992; Shure \& Spivack, 1982). A recent meta-analytic review provides evidence of the efficacy of social problem-solving interventions in increasing social competence in children even at pre-school (Barnes, Wang, \& O'Brien, 2018).

Given the cross-sectional design of the present study, issues concerning causal direction are left open, and need to be explored further in longitudinal research.

\section{Conclusion}

The current study provides a model building on previous which places attachment, rejection and relationships at the core of the development of alcohol dependence. As such it provides a potential focus not only for intervention, but also for prevention starting in childhood. Initially the authors suggest it should be used to guide longitudinal research to provide stronger evidence.

\section{References}

Babor, T. F., Higgins-Biddle, J. C., Saunders, J. B., \& Monteiro, M. G. (2001). AUDIT: The alcohol use disorders identification test: Guidelines for use in primary care (2nd ed.). Geneva, Switzerland: World Health Organization.

Barnes, T. N., Wang, F., \& O'Brien, K. M. (2018). A meta-analytic review of social problem-solving interventions in preschool settings. Infant and Child Development, 27(5), e2095. Available at: https://doi.org/10.1002/icd.2095.

Brookings, J. B., Zembar, M. J., \& Hochstetler, G. M. (2003). An interpersonal circumplex/ five-factor analysis of the Rejection Sensitivity Questionnaire. Personality and Individual Differences, 34, 449-461. Available at: https://doi.org/10.1016/S0191-8869(02)00065-X.

Chango, J. M., McElhaney, K. B., Allen, J. P., Schad, M. M., \& Marston, E. (2012). Relational stressors and depressive symptoms in late adolescence: Rejection sensitivity as a vulnerability. Journal of Abnormal Child Psychology, 4O(3), 369379. Available at: https://doi.org/10.1007/s 10802-01 1-9570-y.

Chesin, M., Fertuck, E., Goodman, J., Lichenstein, S., \& Stanley, B. (2015). The interaction between rejection sensitivity and emotional maltreatment in borderline personality disorder. Psychopathology, 48(1), 31-35. Available at: http://dx.doi.org/10.1159/000365.

Downey, G., Feldman, S., \& Ayduk, O. (2000). Rejection sensitivity and male violence in romantic relationships. Personal Relationships, 7, 45-61. Available at: https://doi.org/10.1177/0886260515609584.

Downey, G., \& Feldman, S. I. (1996). Implications of rejection sensitivity for intimate relationships. Journal of Personality and Social Psychology, 7O(6), 1327-1343. Available at: https://doi.org/10.1037/0022-35 14.70.6.1327.

Downey, G., Khouri, H., \& Feldman, S. I. (1997). Early interpersonal trauma and later adjustment: The mediational role of rejection sensitivity. In D. Cicchetti \& S. L. Toth (Eds.), Developmental perspectives on trauma: Theory, research, and intervention (pp. 85-114). Rochester, NY: University of Rochester Press.

Downey., G., Mougios, V., Ayduk, O., London, B. E., \& Shoda, Y. (2004). Rejection sensitivity and the defensive motivational system: Insights from the startle response to rejection cues. Psychological Science, 15(10), 668-673. Available at: https://doi.org/10.1111/j.0956-7976.2004.00738.x. 
Fairbairn, C. E., Briley, D. A., Kang, D., Fraley, R. C., Hankin, B. L., \& Ariss, T. (2018). A meta-analysis of longitudinal associations between substance use and interpersonal attachment security. Psychological Bulletin, 144(5), 532-555. Available at: https://doi.org/10.1037/bulooo0141.

Fischer, L. J., \& Wiersma, D. J. (2012). Romantic relationships and alcohol use. Current Drug Abuse Reviews, 5(2), 98-116. Available at: https://doi.org/10.2 174/1874473711205020098

Fraley, R. C., Waller, N. G., \& Brennan, K. A. (2000). An item response theory analysis of self-report measures of adult attachment. Journal of Personality and Social Psychology, 78(2), 350-365. Available at: https://doi.org/10.1037/00223514.78.2.350.

Gao, S., Assink, M., Cipriani, A., \& Lin, K. (2017). Associations between rejection sensitivity and mental health outcomes: A meta-analytic review. Clinical Psychology Review, 57, 59-74. Available at: http://dx.doi.org/10.1016/j.cpr.2017.08.007.

Godleski, S. A., Eiden, R. D., Kachadourian, L., \& Lucke, J. F. (2019). Etiological pathways to rejection sensitivity in a high-risk sample. Personality and Social Psychology Bulletin, 45(5), 715-727. Available at: https://doi.org/10.1177/0146167218795486.

Goldstein, A. L., Haller, S., Mackinnon, S. P., \& Stewart, S. H. (2019). Attachment anxiety and avoidance, emotion dysregulation, interpersonal difficulties and alcohol problems in emerging adulthood. Addiction Research \& Theory, 27(2), 130-138. Available at: https://doi.org/10.1080/16066359.2018.1464151.

Hamdan-Mansour, A. M. (2016). Social support and adolescents' Alcohol use: An integrative literature review. Health, 8, 11661177. Available at: http://dx.doi.org/10.4236/health.2016.812120.

Hazan, C., \& Shaver, P. (1987). Romantic love conceptualized as an attachment process. Journal of Personality and Social Psychology, 52(3), 511-524. Available at: https://doi.org/10.1037/0022-3514.52.3.511.

Hocking, E. C., Simons, R. M., Simons, J. S., \& Freeman, H. (2018). Adult attachment and drinking context as predictors of alcohol problems and relationship satisfaction in college students. The American Journal of Drug and Alcohol Abuse, 44(3), 339-347. Available at: https://doi.org/10.1080/00952990.2017.1344682.

Hughes, M. E., Waite, L. J., Hawkley, L. C., \& Cacioppo, J. T. (2004). A short scale for measuring loneliness in large surveys: Results from two population-based studies. Research on Aging, 26(6), 655-672. Available at: https://doi.org/10.1177/0164027504268574.

Khodarahimi, S., Hashim, I. H. M., \& Mohd-Zaharim, N. (2016). Attachment styles, perceived stress and social support in a Malaysian young adults sample. Psychologica Belgica, 56(1), 65-79. Available at: $\underline{\mathrm{http}: / / \mathrm{dx} . \mathrm{doi} . \mathrm{org} / 10.5334 / \mathrm{pb} .320}$.

Krasikova, D. V., Lester, P. B., \& Harms, P. D. (2015). Effects of psychological capital on mental health and substance abuse. Journal of Leadership \& Organizational Studies, 1-12. Available at: https://doi.org/10.1177/1548051815585853.

Laws, H. B., Ellerbeck, N. E., Rodrigues, A. S., Simmons, J. A., \& Ansell, E. B. (2017). Social rejection and alcohol use in daily life. Alcoholism: Clinical and Experimental Research, 41(4), 820-827. Available at: https://doi.org/10.1111/acer.13347.

Lawson, D. M., \& Brossart, D. F. (2013). Interpersonal problems and personality features as mediators between attachment and intimate partner violence. Violence and Victims, 28(3), 414-428. Available at: https://doi.org/10.1891/0886-6708.vv-d$12-00031$.

Leonard, K. E., \& Eiden, R. D. (2007). Marital and family processes in the context of alcohol use and alcohol disorders. Annual Review of Clinical Psychology, 3, 285-310. Available at: https://doi.org/10.1146/annurev.clinpsy.3.022806.091424.

Levitt, A., \& Leonard, K. E. (2015). Insecure attachment styles, relationship-drinking contexts, and marital alcohol problems: Testing the mediating role of relationship-specific drinking-to-cope motives. Psychology of Addictive Behaviors, 29(3), 696. Available at: https://doi.org/10.1037/adboooo064.

Liu, R. T., Kraines, M. A., Massing-Schaffer, M., \& Alloy, L. B. (2014). Rejection sensitivity and depression: Mediation by stress generation. Psychiatry, 77(1), 86-97. Available at: https://doi.org/10.1521/psyc.2014.77.1.86.

Lorenz, T., Beer, C., Pütz, J., \& Heinitz, K. (2016). Measuring psychological capital: Construction and validation of the compound PsyCap scale (CPC-12). PLoS ONE, 11(4), e0152892. Available at: https://doi.org/10.1371/journal.pone.0152892.

Luthans, F., \& Youssef-Morgan, C. M. (2017). Psychological capital: An evidence-based positive approach. Annual review of Organizational Psychology and Organizational Behavior, 4, 339-366. Available at: https://doi.org/10.1 146/annurevorgpsych-032516-1 13324.

Luthans, F., Youssef-Morgan, C. M., \& Avolio, B. J. (2015). Psychological capital and beyond: Oxford University Press.

Luthans, F., Youssef, C. M., Sweetman, D. S., \& Harms, P. D. (2013). Meeting the leadership challenge of employee well-being through relationship PsyCap and health PsyCap. Journal of Leadership \& Organizational Studies, 20(1), 118-133. Available at: https://doi.org/10.1177/1548051812465893.

Malouff, J. M., Thorsteinsson, E. B., \& Schutte, N. S. (2007). The efficacy of problem solving therapy in reducing mental and physical health problems: A meta-analysis. Clinical Psychology Reviere, 27(1), 46-57. Available at: https://doi.org/10.1016/j.cpr.2005.12.005.

Marin, T. J., \& Miller, G. E. (2013). The interpersonally sensitive disposition and health: An integrative review. Psychological Bulletin, 139(5), 941-984. Available at: https://doi.org/10.1037/a0030800.

McGaffin, B. J., Deane, F. P., Kelly, P. J., \& Blackman, R. J. (2018). Social support and mental health during recovery from drug and alcohol problems. Addiction Research \& Theory, 26(5), 386-395. Available at: https://doi.org/10.1080/16066359.2017.1421178.

Journal of Contemporary Research in Social Sciences
ISSN : 264.1-0249
Vol. 3, No. 4, pp. $69-77,2021$
DOI: $10.33094 / 26410249.2021 .34 .69 .77$
C) 2021 by the authors; licensee Learning Gate


McLeod, S., Berry, K., Hodgson, C., \& Wearden, A. (2020). Attachment and social support in romantic dyads: A systematic review. Journal of Clinical Psychology, 76(1), 59-101. Available at: https://doi.org/10.1002/jclp.22868.

Merrill, K. L., Smith, S. W., Cumming, M. M., \& Daunic, A. P. (2017). A review of social problem-solving interventions: Past findings, current status, and future directions. Review of Educational Research, 87(1), 71-102. Available at: https://doi.org/10.3102/0034654316652943.

Nakhoul, L., Obeid, S., Sacre, H., Haddad, C., Soufia, M., Hallit, R., \& Hallit, S. (2020). Attachment style and addictions (alcohol, cigarette, waterpipe and internet) among Lebanese adolescents: A national study. BMC Psychology, 8(1), 1-10.

Newbury-Birch, D., Gilvarry, E., McArdle, P., Ramesh, V., Stewart, S., Walker, J., \& Eileen Kaner, E. (2014). Impact of alcohol consumption on young people: A review of reviews. London: Department for Children, Schools and Families (DCSF).

Pachankis, J. E., Hatzenbuehler, M. L., \& Starks, T. J. (2014). The influence of structural stigma and rejection sensitivity on young sexual minority men's daily tobacco and alcohol use. Social Science and Medicine, 103, 67-75. Available at: https://doi.org/10.1016/j.socscimed.2013.10.005.

Procidano, M. E., \& Heller, K. (1983). Measures of perceived social support from friends and from family: Three validation studies. American Journal of Community Psychology, 11(1), 1-24. Available at: https://doi.org/10.1007/bfo0898416.

Romero-Canyas, R., Downey, G., Berenson, K., Ayduk, O., \& Kang, N. J. (2010). Rejection sensitivity and the rejectionhostility link in romantic relationships. Journal of Personality, 78(1), 119-148. Available at: https://doi.org/10.1111/j.1467-6494.2009.00611.x.

Russell, D., Peplau, L. A., \& Cutrona, C. E. (1980). The revised UCLA loneliness scale: Concurrent and discriminant validity evidence. Journal of Personality and Social Psychology, 39(3), 472-480. Available at: https://doi.org/10.1037/00223514.39.3.472.

Shure, M. (1992). I can problem solve: An interpersonal cognitive problem-solving program. Champaign, IL: Research Press.

Shure, M. B., \& Spivack, G. (1982). Interpersonal problem-solving in young children: A cognitive approach to prevention. American Journal of Community Psychology, 1O(3), 341-356. Available at: https://doi.org/10.1007/bfo0896500.

Struck, N., Krug, A., Feldmann, M., Yuksel, D., Stein, F., Schmitt, S., \& Meinert, S. (2020). Attachment and social support mediate the association between childhood maltreatment and depressive symptoms. Journal of Affective Disorders, 273, 310-317. Available at: https://doi.org/10.1016/j.jad.2020.04.041.

Taylor, S. E. (2011). Social support: A review. In H. S. Friedman (Ed.), The Oxford handbook of health psychology. Oxford: Oxford University Press.

Watson, J., \& Nesdale, D. (2012). Rejection sensitivity, social withdrawal, and loneliness in young adults. Journal of Applied Social Psychology, 42(8), 1984-2005. Available at: http://dx.doi.org/10.1111/j.1559-1816.2012.00927.x.

Journal of Contemporary Research in Social Sciences
ISSN : 2641-0249
Vol. 3, No. 4, pp. $69-77,2021$
DOI: $10.33094 / 26410249.2021 .34 .69 .77$
C) 2021 by the authors; licensee Learning Gate

